\title{
Employee Organizational Commitment
}

\author{
Života Radosavljević́ ${ }^{3}$, Vesna Ćilerdžić4 ${ }^{4}$ Milan Dragić 5
}

\begin{abstract}
This paper shows the results of research on organizational commitment as a type of attitudes that show the identification level of employees with their organizations and their willingness to leave them. The research has been conducted with intention to determine the level of organizational commitment on the territory of Novi Sad, as well as to question whether there is a difference between certain categories of examinees for each commitment base. The research comprised 237 examinees employed in organizations on the territory of Novi Sad. Status of independent variables have gained: gender, years of working experience, educational level, working experience in one or more organizations and estimation of level of personal potentials utility. The questionnaire used is taken from the Greenberg and Baron's "Behaviour in Organizations", p. 170, done according to set of questions by Meyer and Allen, in 1991. The data have been worked on by calculating arithmetic mean, and by application of Pearson Chisquare test. The results have shown that there is a below average level of organizational $(A S=2.88)$, with the most intensive continual $(A S=3.23)$, and the least intensive normative organizational dedication $(A S=2.41)$. The gender of examinees does not represent relevant source of differences in the levels of each type of three mentioned commitment. Years of working experience and level of educational attainment represent a significant source of differences for continual (YWE: Pearson Chi-square $=30,38 ; d f=8 ; p=.000)($ LEA: Pearson Chi-square $=7,381 ; d f=2 ; p=.05)$ and normative (YWE: Pearson Chi- square $=20,67 ; d f=$ $8 ; p=.000)$ (LEA: Pearson Chi-square $=10,79 ; d f=2 ; p=.00)$ base of commitment. Work in one or more organizations has shown as a significant source of differences in the level of continual commitment (Pearson Chi-square $=7,59 ; d f=2 ; p=.05$ ). The level of affective commitment is statistically significantly related only to the estimation of level of personal potentials utility of examinees. (Pearson Chi-square $=22,99 ; d f=4 ; p=.00$ ).
\end{abstract}

KEY WORDS: Organizational Commitment, Research on Organizational Commitment, Commitment

JEL: J24, J28

UDC: 005.961:005.336.1

005.32

COBISS.SR-ID 238303756

\footnotetext{
${ }^{3}$ Faculty for business studies and law, University „Union - Nikola Tesla“, Belgrade, Serbia,e-mail: zivota.radosavljevic@fpsp.edu.rs

${ }^{4}$ Faculti of management, Sremski Karlovci, University „Union - Nikola Tesla“, Belgrade, Serbia

${ }^{5}$ Faculty for Business Economics and Entrepreneurship, Belgrade, Serbia, Serbia
} 


\section{INTRODUCTION}

No organization in today's competitive world can have superior performance unless every employee is committed to the goals of the organization and unless he/she does not work as an effective team member. It is no longer sufficient to have employees who come faithfully every day to work and do their work independently. Employees should now think like entrepreneurs, working in teams and proving their value. However, they would also want to be part of a successful organization that provides a good income and the opportunity for development, and secure employment. In the past, organizations have ensured the loyalty of its employees by guaranteeing job security. However, many organizations have responded to competitive pressures by layoffs, restructuring and transformation, creating uncertain organizational climate. Employees, therefore, feel that they are victims of broken promises. One of the challenges faced by modern organizations includes maintaining employee commitment in the current business environment. It can be achieved by an organization through the development of new "contract of employment". In workplaces today, employees are faced with more uncertainties in their daily activities and reduced job security (Bergmann, Lester, De Meuse and Grahn, 2000). Without the certainty of continuous employment, workers have raised their expectations in other areas. For example, employees expect that employers create with dedication a pleasant working environment, facilitate the accessibility of training and development for employees, provide a safe working environment and a balance between work and obligations of workers out of the workplace. Organizations are faced with the trend of always growing competition as they prepare for new challenges. One of the key components of survival is the maintenance and improvement of the organizational possibility of human resources utilization in an effective and efficient manner. According to Katz (1964), the behaviors of employees which are essential for organizational effectiveness include (1) a job in the organization and their survival in it, (2) the implementation of specific requirements, and (3) participation in innovative and spontaneous activities beyond their core roles. Setting diligent workers for non-managerial workplace is important, but more relevant is the organizational ability to create dedicated workforce. Therefore there is a need for managers to understand the concept of commitment - what it is, how it works, and what is most important, which behaviours imply a commitment of worker to some organization. The importance of employee commitment is evident in studying the link between commitment and job satisfaction (Bateman \& Organ, 1983), satisfying justice in the workplace (Moorman, Niehoff, Organ, 1992), trust in the leader and loyalty to him (Deluga, 1994), and understanding that the supervisor is righteous (Niehoff, Moorman, 1993).

Obviously, organizational behavior that is to create long-term value should not rely on the management that is manipulating people nor through controls or incentives. It means creating the system of values that enables all the participants in the organization to take part in the creative process of doing business, acknowledge their significance and point out the value of their efforts. (Stojanović, Djokic, Djokic, 2013) 


\section{THEORETICAL BASES - DEFINING COMMITMENT}

For years, the commitment has been defined and measured in different ways. In fact, the lack of consensus in defining this term greatly contributed to its treatment as a multidimensional construct (Meyer, Allen, 1991). Even if there are more dimensions or form of commitment, there must be a core marking it. To determine what the essential core is, what is common among existing conceptualities should be sought. However, the authors do not agree on the nature of attitudes and therefore different types (dimensions) of commitment identified by them. Three component- conceptualization of organizational commitment

According to Meyer, Allen (1991), organizational commitment is reflected in at least three general topics: active association with the organization, the predictable costs of leaving the organization and the obligation to remain in the organization. These three approaches are called affective, continual and normative commitment. Common to these three approaches is the attitude that the commitment is a psychological state characterized by the relationship of employees to the organization and implies a decision to continue the work in it. These psychological states also have different implications for the behavior related to the workplace.

Affective commitment refers to the employee's emotional attachment to the organization, its identification with the organization and involvement in its operation, namely, the agreement of objectives of the organization and of the individual. This is good. Employees who are very affectively dedicated to organization remain in it because they want to. According to Mowday (1982), the causes of affective commitment narrow down to four categories: (1) personal characteristics, (2) structural characteristics (organizational), (3) the characteristics related to the type of work being performed, and (4) work experience. Although several researches were conducted for the purpose of integration of demographic characteristics (age, social status, gender and education level) to connect to the commitment, the resulting degree of correlation is not consistent. There are too many variables, such as job status, remuneration and working values that further affect the degree of this dependency. Few studies deal with the relationship between organizational characteristics and commitment. However, the results indicate the connection between affective commitment and the decentralization of decision-making and formalization of policies and procedures of the organization. In addition, a significant number of studies were conducted dealing with the relationship between the variables of work experience of employees and their affective commitment. Variables of work experience that are correlated with affective commitment include equality in the distribution of rewards, clarity of roles and freedom from conflict, caution of supervisors, justice of rewarding versus performance and challenges of the work itself, the opportunity for advancement and participation in decision-making.

Continual commitment refers to the awareness of the costs associated with leaving the organization. The potential costs of leaving the organization involve the threat of wasting time and effort spent on the acquisition of non-communicable skills, loss of attractive benefits, waiver of privilege that brings long years of service, and the collapse of family and personal partnerships. In addition to costs related to leaving the organization, continual commitment will also develop in the absence of alternative employment opportunities. Employees staying in the organization because of the continual commitment remain in them because they have to.

Employees with high levels of normative commitment feel that they are obliged to remain in the organization. Wiener (1982) points out that this sense of obligation to remain in the organization can be realized from the internalization of normative pressures on the individual primarily to approach the organization itself (family or cultural reasons) or from the organizational orientation when influential individuals in the employee environment can exercise strong pressure on the employee to feel a moral responsibility towards the organization. However, normative commitment can also develop when the organization allows 
employees to be awarded in advance (for example, that they are paid tuition fees for faculty) or compensates significant costs for the provision of employment (e.g. compensation for "hunting employees "or the costs associated with training for the job). Identifying these investments causes employees to feel obliged to commit to the organization until payment of the debt.

Commitment and behaviour at work. The meaning of commitment of employees can best be explained using the theory of social exchange. The theory of social exchange is based on an economic model of human behavior, where the interaction processes between individuals are motivated by the desire to increase the rewards and reduce losses. The basic premise of the theory of social exchange is that the relationships that provide more reward than costs contribute to permanent mutual trust and attachment. Furthermore, these social transactions include both material benefits and psychological rewards, including status, loyalty and approval. For example, the workplace supervisor enables the employees cash rewards, while in return the employee contributes by the personal commitment and expertise. Most often studied behavior that is correlated with the commitment is money turnover in an organization. However, that focus on the turnover can be short-sighted. Organizational performance depends more than just on simple maintenance of a stable workforce; employees have to perform assigned duties by relying on each other and must be willing to engage in activities that go beyond the role requires. Therefore, it seems reasonable to presume that the willingness of employees to contribute to the organizational performance will be influenced by the nature of the commitment they feel. Employees who wish to belong to the organization (affective commitment), as opposed to those who feel they need to belong (continuous commitment), or those who feel obliged to belong (normative commitment) are willing to make efforts for the benefit of their organization. Interestingly, of the studies registering correlations between commitment and performance, most of them used measures of affective commitment. It is possible that the obligation to remain in the organization carries with itself the obligation to contribute to it and, in that case the normative commitment is positively correlated with the efforts and performance. Continual commitment is perhaps the least likely option for a positive correlation with the performance. Employees whose term of office in the organization is based primarily on the needs may have little reason to do more than is necessary in order to maintain their existence in the organization. Organizations need employees who are willing to perform tasks that go beyond their standard duties and expectations of them, and to engage in additional activities at work. For this reason, the research will continue to examine the connection between these three components of commitment and multidimensional measurability of behavior at work. Meyer and Allen discovered that the measurability of conduct at work is positively correlated with measures of affective and normative commitment, but not with the continual commitment. Research conducted by Randall, Fedor and Longenecker (1990) reveals that affective commitment contributes significantly to the prediction of items related to the quality, readiness to sacrifice, and a willingness to share the knowledge. Normative commitment contributes only to the assumption about the readiness to sacrifice; a continuous commitment did not provide any significant predictions regarding this organizational behavior. The new findings therefore support the proposal that the three components of commitment have different implications for the behavior at work other than turnover. The term closely linked to the commitment is the organizational "citizenship". It can be conceived as a global concept that includes all the positive, organizationally relevant behavior of individual members of the organization. Therefore it includes traditional jobs that have defined roles, functional behavior with additional roles and political behaviors such as full and responsible participation in the organization, that were usually omitted in previous studies of "citizenship". 


\section{EMPIRICAL RESEARCH}

The problem of this study is assessing the level of organizational commitment of employees in various organizations of Novi Sad. The theoretical AIM of this study is to determine whether there are, and if there are any relations of organizational commitment and individual characteristics of the subjects. Practical goal of this paper consists in the draft of procedures that would result in higher level of affective commitment.

\section{Hypotheses}

The general hypothesis from which we start the study reads as follows: among the respondents is present below-average organizational commitment.

H1: The most common is a continual commitment.

$\mathrm{H} 2$ : The least represented is the affective commitment.

H3: The gender is not a significant source of differences in the bases of commitment.

H4: Years of service are not a significant source of differences in the bases of commitment.

H5: Level of educational attainment is not a significant source of differences in the bases of commitment.

H6: Working in one or more organizations is not a significant source of differences in the bases of commitment.

H7: Evaluation of the degree of utilization of the labor potential is not a significant source of differences in the bases of commitment.

\section{Methodology}

The sample of variables

The independent variables of this research are: gender, years of work experience, educational level of attainment, the number of organizations in which the employee worked, as well as the assessment of the degree of utilization of the labor potential of respondents. Dependent variables are 12 offered statements, according to the key sorted into three basic organizational commitments.

\section{The sample of respondents}

The sample of respondents consists of 237 employees in the territory of Novi Sad. Organizations in which the questionnaire is distributed were chosen by random, and the sample included those that were employed at the day of placing the questionnaire and who accepted to participate in the study. This indicates that the sample has the characteristics of both occasional and random, but it can be said that it is representative, and the obtained data are relevant. The structure of the sample of respondents according to the independent variables is shown in Table 1.

Table 1:The sample of respondents according to the independent variables

\begin{tabular}{||l|l|l|l||}
\hline \hline VARIABLE & REPLY & FREQUENCY & PERCENTAGE \\
\hline Gender & Female & 164 & 69,2 \\
\cline { 2 - 4 } & Male & 73 & 30,8 \\
\hline \multirow{4}{*}{ Years of working experience } & up to 2 years & 24 & 10,1 \\
\cline { 2 - 4 } & $2-5$ years & 35 & 14,8 \\
\cline { 2 - 4 } & $6-10$ years & 59 & 24,9 \\
\cline { 2 - 4 } & $11-15$ years & 43 & 18,1 \\
\cline { 2 - 4 } & $16-25$ years & 46 & 19,4 \\
\cline { 2 - 4 } & $26-35$ years & 25 & 10,5 \\
\cline { 2 - 4 } & more than 36 years & 5 & 2,1 \\
\hline
\end{tabular}




\begin{tabular}{||l|l|l|l||}
\hline \multirow{4}{*}{ Level of educational attainment } & Primary school & 7 & 3,0 \\
\cline { 2 - 4 } & Secondary school & 130 & 54,9 \\
\cline { 2 - 4 } & High school & 37 & 15,6 \\
\cline { 2 - 4 } & Faculty & 58 & 24,5 \\
\cline { 2 - 4 } & $\begin{array}{l}\text { Masters degree, doctoral } \\
\text { degree }\end{array}$ & 5 & 2,1 \\
\hline \multirow{3}{*}{ You worked in } & One company & 105 & 44,3 \\
\cline { 2 - 4 } & Several companies & 130 & 54,9 \\
\cline { 2 - 4 } & No reply & 2 & 8 \\
\hline $\begin{array}{l}\text { Assess the extent to which your } \\
\text { work potential is positive utilized } \\
\text { (used) }\end{array}$ & Completely & 93 & 39,2 \\
\cline { 2 - 4 } & Partly & 115 & 48,5 \\
\cline { 2 - 4 } & Extremely poor & 28 & 11,8 \\
\cline { 2 - 3 } & No reply & 1 & 4 \\
\hline
\end{tabular}

\section{Research methods and instruments for data collection}

The paper used the method of field research. Instrument for data collection was taken from the book by Greenberg and Baron, "Behavior in Organizations " (page 170), done on the basis of questions by Meyer and Allen, 1991. It contains 12 offered statements, and the respondent answers by expressing their level of his/her agreement with each statement individually on a five-point Liker scale, from lowest (completely disagree) to the highest (strongly agree).

The data obtained were analyzed by determining the average value on an aggregate level and for each bases of commitment individually. In order to establish the existence of differences between certain categories of respondents for each individual basis of commitment the Chi-square test of independence of characteristics was applied. Five-point scale of answers of the respondents was reduced to a three-stage, and the summing up of some categories of respondents.

The study was conducted in the first half of 2016. Employees were examined at their workplaces. Following short instructions for filling out the questionnaire, noting that the examination is anonymous, the respondents started filling the questionnaire. The filling out of questionnaire lasted on average 10 minutes. In some companies there were incorrectly completed questionnaires, indicating a lack of interest in this topic, or unwillingnessimpossibility for honest answers, and these questionnaires were not taken into account when processing the data.

\section{The results display with discussion}

By determining the level of organizational commitment, which is AS $=2.88$, we have confirmed the general hypothesis of the research: At the employed in the territory of Novi Sad below the average level of organizational commitment is present. Observing each basis of organizational commitment individually, we found that the continual is most common (AS = 3.23 ), followed by the affective ( $\mathrm{AS}=3.01$ ), and finally the normative ( $\mathrm{AS}=2.41$ ). These results support the first special hypothesis, which states: the most common is the continual basis of commitment; and refute the second special hypothesis, which states: the least represented is the affective basis of commitment.

In order to investigate the influence of certain characteristics of the subjects on individual bases of organizational commitment data were analyzed using the chi-square test. The results show that among respondents of different gender there is no statistically significant difference on every individual basis of organizational commitment. Therewith the third special hypothesis is accepted.

The data presented in Table 2 show that the years of working experience of the respondents is statistically significant source of variation at the level of continual bases of commitment to the organization (Chi- Square $=30.38, \mathrm{df}=8 ; \mathrm{p}=0.00$ ). With increasing years of working experience the continual commitment to organization is also growing. 
Table 2: Continual basis of commitment and years of $w$. expirience

\begin{tabular}{||l|l|l|l|l|}
\hline \multirow{2}{*}{ Years of working experience } & \multicolumn{2}{|l|}{ Continual commitment } & \multirow{2}{*}{ Total } \\
\cline { 2 - 4 } & Low & Average & High & \\
\hline up to 5 & 26 & 18 & 14 & 58 \\
\hline $6-10$ & 22 & 24 & 12 & 58 \\
\hline $11-15$ & 6 & 21 & 15 & 42 \\
\hline $16-25$ & 8 & 13 & 25 & 46 \\
\hline $26-35$ & 4 & 9 & 14 & 27 \\
\hline Total & 66 & 85 & 80 & 231 \\
\hline \multicolumn{4}{|l}{} \\
\hline
\end{tabular}

The result is not surprising, considering that employee working for a long time in the same place accumulates investments such as: time, relationship with colleagues, the position that can not be transmitted if he/she changes the organization. Table 3 contains data on the basis of which we can see that there is a statistically significant effect of years of working experience of the respondents to the level of normative basis for commitment to the organization (Chi Square $=20.67 ; \mathrm{df}=8 ; \mathrm{p}=0.00$ ). At the majority of the respondents with the length of service to 10 years there is a low normative commitment, while at the respondents with more than 16 years of working experience more present is high normative commitment.

Table 3: Normative basis of commitment and years of working experience

\begin{tabular}{||l|l|l|l|l|}
\hline \hline \multirow{2}{*}{ Years of working experience } & \multicolumn{2}{l|}{ Normative commitment } & \multirow{2}{*}{ Total } \\
\cline { 2 - 5 } & Low & Average & High & \\
\hline up to 5 & 24 & 18 & 16 & 58 \\
\hline $6-10$ & 22 & 19 & 17 & 58 \\
\hline $11-15$ & 8 & 19 & 16 & 43 \\
\hline $16-25$ & 8 & 16 & 20 & 44 \\
\hline $26-35$ & 3 & 8 & 17 & 28 \\
\hline Total & 65 & 80 & 86 & 231 \\
\hline \multicolumn{2}{|l|}{ Pearson Chi-square $=20,67 ; \mathrm{df}=8 ; \mathrm{p}=.000$} \\
\hline
\end{tabular}

The results indicate that with the respondents having fewer years of work experience feel less obligation and pressure of the environment to stay in an organization where they already work in, and vice versa, as respondents have more years of experience it is a more common reason of their commitment to the organization due to the pressure of the environment.

The data presented in the table below show a statistically significant effect of educational attainment level on the level of continual commitment, whereby the connection is inversely proportional: at respondents with a lower level of education more often present is high continual commitment, as well as among the respondents with higher education levels of educational attainment more often present is low continual commitment to the organization (Pearson Chi-square $=7.381, \mathrm{df}=2, \mathrm{p}=.05$ ).

Table 4: Continual basis of commitment and level of educational attainment

\begin{tabular}{|l|l|l|l|l||}
\hline \multirow{2}{*}{ Years of working experience } & Continual commitment & \multirow{2}{*}{ Total } \\
\cline { 2 - 4 } & Low & Average & High & \\
\hline Secondary school & 29 & 49 & 53 & 131 \\
\hline High school and higher & 37 & 36 & 27 & 100 \\
\hline Total & 66 & 85 & 80 & 231 \\
\hline Pearson Chi-square $=7,381 ; \mathrm{df}=2 ; \mathrm{p}=.05$ & \multicolumn{2}{l}{} \\
\hline
\end{tabular}


The result suggests the conclusion that the more respondents are educated the less they "go for the safe bet", i.e. the reason of their commitment are less and less invisible investments (building up the positions, relationships with colleagues) which they invested over time working in this organization. These relationships ensure security and privileges that employees with a higher level of education consider less important reason for the commitment to the organization. The obtained results (Table 5) indicate that there is a statistically significant difference in levels of normative commitment depending on the degree the level of educational attainment of the respondents (Pearson Chi-square $=10.79$, df $=2, \mathrm{p}=.00$ ). The lower level of educational attainment of respondents the more present is high normative commitment to the organization.

Table 5: Normative commitment and the level of educational attainment

\begin{tabular}{||l|l|l|l|l||}
\hline \hline \multirow{2}{*}{ Years of working service } & \multicolumn{2}{|l|}{ Continual commitment } & \multirow{2}{*}{ Total } \\
\cline { 2 - 5 } & Low & Average & High & \\
\hline High school & 33 & 38 & 61 & 132 \\
\hline High school and higher & 32 & 42 & 25 & 99 \\
\hline Total & 65 & 80 & 86 & 231 \\
\hline Pearson Chi-square $=10,79 ; \mathrm{df}=2 ; \mathrm{p}=.00$ &
\end{tabular}

As the normative basis of commitment arises from feeling of obligation to remain in the current organization, imposed by the environment or influential individual in the organization, the result is not surprising that it is more present in subjects with lower levels of educational attainment. The result can be explained by the growing competition in the labor market when those with higher levels of educational attainment have a better chance of employment. The largest number of workers with the highest completed high school are under pressure of the environment, and despite the dissatisfaction related to work, they do not undertake much to change that. That there is a statistically significant effect (Pearson Chi-square $=7.59, \mathrm{df}=2, \mathrm{p}=$ $.05)$ in the number of organizations in which

the respondents have worked on the level of the continual commitment is shown by the data in Table 6. The relationship goes in the sense that the more the respondents worked in several organizations the more present was a higher level of continual commitment, and vice versa, working in one organization is often associated with more present low level of continual commitment to the organization.

Table 6: Continual basis of commitment and the number of companies in which the respondents worked

\begin{tabular}{|l|l|l|l|l||}
\hline \multirow{2}{*}{ Up to now you worked in } & \multicolumn{2}{|l|}{ Continual commitment } & \multirow{2}{*}{ Total } \\
\cline { 2 - 4 } & Low & Average & High & \\
\hline one organization & 37 & 36 & 27 & 100 \\
\hline several organizations & 28 & 49 & 52 & 129 \\
\hline Total & 65 & 85 & 79 & 229 \\
\hline Pearson Chi-square $=7,59 ; \mathrm{df}=2 ; \mathrm{p}=.05$ & \multicolumn{2}{|l}{} \\
\hline
\end{tabular}

Years of working experience in at least two organizations proved to be a major characteristic of the level of organizational commitment, when we see in the results that the experience of changing the organization strengthens awareness of the material and "psychological" costs. Table 7 presents the research results of the impact of assessment of the degree of use of personal resources to the level of affective commitment to the organization. A statistically significant difference was obtained (Pearson Chi-square $=22.99, \mathrm{df}=4, \mathrm{p}=.00$ ), in the sense that among the respondents who assess that their potentials are extremely low used the workplace more present is low affective commitment, and vice versa: among the respondents who think that their potential is fully used more frequent is a high affective commitment to the organization. 
Table 7: Affective basis of commitment and assessment of the degree of use of personal potentials

\begin{tabular}{||l|l|l|l|l||}
\hline \multirow{2}{*}{$\begin{array}{l}\text { To what extent is your work } \\
\text { potential used positively }\end{array}$} & \multicolumn{2}{l|}{ Continual commitment } & Total \\
\cline { 2 - 4 } Completely & Low & Average & High & \\
\hline Partly & 18 & 41 & 31 & 90 \\
\hline Extremely poor & 41 & 42 & 27 & 110 \\
\hline Total & 19 & 6 & 3 & 28 \\
\hline Pearson Chi-square $=22,99 ; \mathrm{df}=4 ; \mathrm{p}=.00$ & 89 & 61 & 228 \\
\hline
\end{tabular}

Given the theoretical determination of the affective basis of organizational commitment the result obtained was expected. It was confirmed that the agreement of individual and organizational goals, results in a higher degree of engagement of the workers.

\section{CONCLUSION}

Gender, as a characteristic of the respondents, did not show a statistically significant association with any basis of organizational commitment. Years of working experience and level of education were significantly associated with continual and normative bases of organizational commitment, while working in one or more organizations and personal evaluation of the level of utilization of working potential were linked only by one basis of organizational commitment. The affective basis of commitment showed a statistically significant relationship with only one observed characteristic: personal evaluation on the utilization of working potentials.

\section{REFERENCES}

[1] Bateman, T.S., Organ, DW. (1983). Job satisfaction and the good soldier: the relationship of employee commitment: an exploratory study. Journal of Applied Business Research, 16(4):15- 27.

[2] Bergmann, T.J., Lester, S.W., De Meuse, K.P., Grahn, J.L. (2000). Integrating the three domains between affect and employee citizenship. Academy of Management Journal, 26:587-595.

[3] Grinberg, Dž., Baron, R. A. (1998). Ponašanje u organizacijama, Želnid, Beograd.

[4] Katz, D. (1964). The motivational basis of organizational behavior. Behavioral Science, 9:131-133.

[5] Meyer, J.P.,Allen, N.J. (1987). A longitudinal analysis of the early development and consequences of organizational commitment, Canadian Journal of Behavioural Science, 19:199-215.

[6] Moorman, R.H., Niehoff, B.P.,Organ, D.W. (1992). Treating employees fairly and organizational citizenship behavior: sorting out the effects of job satisfaction, organizational commitment, and procedural justice. Annual meeting of the Academy of Management, Las Vegas, NV.

[7] Niehoff, B.P., Moorman, R.H. (1993). Justice as a mediator of the relationship between methods of monitoring and organizational citizenship behavior. Academy of Management Journal, 36:527-556.

[8] Strojanovic, T., Djokic, A., Djokic, S (2013). Organizational Behavior-Creative Tool for Creating Value, International Review, No. 1-2

\section{Article history:}

- $\quad$ Received 16 September 2016

- Accepted 15 March 2017 